\title{
ORIGINAL ARTICLE School food environments associated with adiposity in Canadian children
}

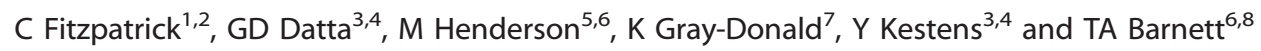

BACKGROUND/OBJECTIVES: Targeting obesogenic features of children's environment that are amenable to change represents a promising strategy for health promotion. The school food environment, defined as the services and policies regarding nutrition and the availability of food in the school and surrounding neighborhood, is particularly important given that students travel through the school neighborhood almost daily and that they consume a substantial proportion of their calories at school.

SUBJECTS/METHODS: As part of the Quebec Adipose and Lifestyle Investigation in Youth (QUALITY) cohort study, we assessed features of school indoor dietary environment and the surrounding school neighborhoods, when children were aged 8-10 years (2005-2008). School principals reported on food practices and policies within the schools. The density of convenience stores and fast-food outlets surrounding the school was computed using a Geographical Information System. Indicators of school neighborhood deprivation were derived from census data. Adiposity outcomes were measured in a clinical setting 2 years later, when participants were aged 10-12 years (2008-2011). We conducted cluster analyses to identify school food environment types. Associations between school types and adiposity were estimated in linear regression models.

RESULTS: Cluster analysis identified three school types with distinct food environments. Schools were characterized as: overall healthful (45\%); a healthful food environment in the surrounding neighborhood, but an unhealthful indoor food environment (22\%); or overall unhealthful (33\%). Less healthful schools were located in more deprived neighborhoods and were associated with greater child adiposity.

CONCLUSIONS: Despite regulatory efforts to improve school food environments, there is substantial inequity in dietary environments across schools. Ensuring healthful indoor and outdoor food environments across schools should be included in comprehensive efforts to reduce obesity-related health disparities.

International Journal of Obesity advance online publication, 14 March 2017; doi:10.1038/ijo.2017.39

\section{INTRODUCTION}

Obesity occurs within multiple settings that influence childhood dietary and physical activity behavior. ${ }^{1,2}$ Environmental targets that are amenable to improvements and modification are especially appealing for intervention. Acknowledging its potential as an upstream determinant of health, experts increasingly recommend including schools as desirable targets for child health promotion efforts. ${ }^{3,4}$

Comprehensive school health programs have outlined strategies for addressing the school food environment. ${ }^{5}$ These programs involve promising strategies for improving the food environment within the school. However, both the indoor and surrounding school food environments are important given that many students consume at least one-third of their daily calories at school, and that daily commutes provide students with numerous food purchasing opportunities. ${ }^{6-8}$

Despite historical resistance from various stakeholders ${ }^{9}$ and ongoing challenges, ${ }^{10-12}$ there is a generally favorable disposition towards implementing healthful policies targeting indoor food environments in schools, with several studies documenting favorable impacts across many regions in Canada. ${ }^{13,14}$ These include positive effects particularly with respect to the availability of fruits and vegetables, and to restricting access to unhealthy beverages. ${ }^{15-17}$ Favorable impacts on body weight have also been reported. ${ }^{18}$ Less is known about how the environment surrounding schools may influence child health outcomes. ${ }^{17}$ Moreover, few policies address the food environment in the surrounding school neighborhood.

Despite a renewed willingness to improve the indoor food environment, stakeholders have expressed frustration and remain stymied by the access to unhealthy food sources in the school surroundings. ${ }^{19}$ Fast-food outlets and convenience stores tend to cluster around schools ${ }_{1}^{20,21}$ particularly those located in disadvantaged neighborhoods. ${ }^{21-23}$ This represents an important public health concern, as well as an opportunity to improve the health of disadvantaged children who already face greater cumulative risks for the development of obesity than their more advantaged peers. ${ }^{24,25}$

What remains to be examined is whether the overall food environment surrounding schools is associated with obesityrelated outcomes among students. For example, improving only the indoor food environments may lead to unintended consequences, ${ }^{18}$ such as encouraging students to purchase food

\footnotetext{
${ }^{1}$ Department of Social Sciences, Sainte-Anne University, Church Point, Nova Scotia, Canada; ${ }^{2}$ Exercise Science and PERFORM Centre, Concordia University, Montreal, Quebec, Canada; ${ }^{3}$ Department of Social and Preventive Medicine, Université de Montréal, Montreal, Quebec, Canada; ${ }^{4}$ Centre de recherche du Centre hospitalier de l'Université de Montréal (CRCHUM), Montreal, Quebec, Canada; ${ }^{5}$ Department of Pediatrics, Université de Montréal, Montreal, Quebec, Canada; ${ }^{6}$ Centre de recherche du CHU Sainte-Justine, Montréal, Quebec, Canada; ${ }^{7}$ School of Dietetics and Human Nutrition, McGill University, Montreal, Quebec, Canada and ${ }^{8}$ Epidemiology and Biostatistics Unit, Centre INRS-Institut Armand-Frappier, Université du Québec, Laval, Québec, Canada. Correspondence: Professor TA Barnett, Epidemiology and Biostatistics Unit, Centre INRS-Institut ArmandFrappier, Université du Québec, 531 Boulevard des Prairies, Laval, Quebec, Canada H7V 1 B7.
}

E-mail: tracie.barnett@iaf.inrs.ca

Received 31 January 2016; revised 15 November 2016; accepted 31 January 2017; accepted article preview online 10 February 2017 
in surrounding establishments. Greater understanding of how the combined influence of food establishments near schools as well as features of the food environment inside schools contribute to the overall healthfulness of students' food environments is therefore needed to better inform comprehensive school health policies.

In the present study, we attempt to identify school types, that is, groupings of schools that are similar based on selected features of the school food environment. This approach allows us to examine how settings of interest influence outcomes as a whole. Furthermore, this strategy is useful for identifying subgroups of schools that may most likely benefit from targeted intervention. We also examine whether school type is related to neighborhood deprivation in order to better understand potential inequities in school health. Finally, we explored the relation between school type, measured at baseline and child adiposity outcomes 2 years later. We anticipated that less healthful school food environment types would (i) be located to a greater extent in neighborhoods with greater material and social deprivation, and (ii) be associated with greater child adiposity 2 years later.

\section{MATERIALS AND METHODS}

\section{Sample}

Participants were followed longitudinally in the context of the Quebec Adipose and Lifestyle Investigation in Youth (QUALITY) cohort study, ${ }^{26}$ an ongoing study of the natural history of obesity in youth at risk due to their parental history. To be eligible, children had to have at least one obese parent, defined as having a body mass index $(\mathrm{BMI})>30 \mathrm{~kg} \mathrm{~m}^{-2}$ or an elevated waist circumference $(>102 \mathrm{~cm}$ in males and $>88 \mathrm{~cm}$ in females). ${ }^{27}$ In addition, to be included, children had to be between the ages of 8 and 10 years, Caucasian, and both biological parents had to be available to participate at baseline. A total of 1040 primary schools from Montreal, Quebec city and Sherbrooke agreed to distribute flyers, representing $89 \%$ of those who were approached. A total of 3350 interested families contacted the research coordinator, and of these 1320 met the study inclusion criteria. For feasibility reasons, school neighborhoods were only assessed for children living in the Montreal Metropolitan Area $(N=512)$ and therefore our final sample is limited to families living in this urban area. Of these, 431 children attended schools in which school principals accepted to participate in the study; these children were clustered within 246 schools.

\section{Study design}

Baseline data collection (both child- and school-level) took place in 20052008 , when participants were between the ages of 8 and 10 years. Followup child-level measures were taken $\sim 2$ years later (2008-2011) when youth were between the ages of 10 and 12 years. At both data collection waves, biological and physiological measurements were obtained from children and parents during a clinic visit. Anthropomorphic measurements and body composition were also obtained from children at both times (see details below). Written informed consent was obtained from parents and principals, and assent was provided by children. Participants were not compensated for their participation. The ethics review boards of $\mathrm{CHU}$ Sainte-Justine and Laval University approved the study protocol. A more detailed description of the study design and methods is available elsewhere. ${ }^{26}$

\footnotetext{
Measures

School environment. Trained research assistants conducted interviews with school principals to record specific features of the school food environment. Prior to the data collection, a pre-test was conducted with four principals to establish the validity of the questionnaires. Following the pre-test, the questionnaire was modified for clarity prior to data collection. Response categories were then carefully derived from answers to the open-ended questions. Specific questions related to school nutrition were informed by the Institute of Medicine Recommendations for Schools to Address Childhood Obesity, the School Health Index, the School Heath Policy and Programs Survey and the Coalition for School Nutrition. ${ }^{28-30}$ Principals reported their agreement with the following statements concerning the indoor school environment: (i) the cafeteria menu must be reviewed by a nutritionist and (ii) the school sells food and drinks that
}

conform to the principles of healthful nutrition. Nutritionists in all Canadian provinces generally have the same qualifications as dieticians. This includes a master's or bachelor's degree in dietetics, nutrition or related field and registration with a regulatory body. Responses were made using a Likert scale with options: 1 (strongly agree); 2 (agree more or less); 3 (disagree more or less); and to 4 (strongly disagree). The distributions of both of these variables were skewed. As a result, it made statistical and practical sense to categorize schools as 'strongly agree' vs 'not strongly agree'. Items were therefore dichotomized as either 0 (strongly agree, that is, healthful indoor school environment) or 1 (not strongly agree, that is, unhealthful indoor school environment).

The characteristics of food environments surrounding children's schools were obtained at baseline using a Geographic Information System. We relied on data from the Montreal Epidemiological and Geographical Analysis of Population Health Outcomes and Neighborhood Effects (MEGAPHONE), a Geographic Information System built for health research that contains spatial information for most Canadian urban areas, including the entire greater Montreal area. Information and location of convenience stores and fast-food outlets were obtained from the ZipCom commercial database, which contains an exhaustive inventory of businesses located in the region as of May 2005. Food sources were categorized using the Standardized International Classification codes and further identified using keyword targeting the business name; a previous study has shown the validity and classification to be good, including for fast-food restaurants and convenience stores. ${ }^{31}$

The Geographic Information System was utilized to identify and map convenience stores and fast-food restaurants within a $750 \mathrm{~m}$ road network buffer for each school. The average density of convenience stores and fastfood restaurants was computed using kernel densities, which are commonly used in geographical estimation to assess the probability distribution of point-based data irrespective of arbitrary administrative boundaries and have been used previously to examine neighborhood access to food establishments. ${ }^{29,32}$ The density scores for convenience stores and fast-food restaurants were dichotomized at the 67th and 64th percentile, respectively, to reflect natural breaks in the distribution of these variables. Densities below the cutoffs were scored as 0 and densities above the cutoffs were scores as 1, with 1 reflecting a less healthful food environment. Each dichotomized score was considered separately in the analyses.

School neighborhood characteristics were based on 2006 census data capturing each census dissemination area within a $750 \mathrm{~m}$ street network surrounding the school. The material deprivation index reflects the proportion of individuals without a high school diploma, who are unemployed and who earn below the average income. The social deprivation index score combines the proportion of people living alone, separated, divorced or widowed, or living in single-parent families. ${ }^{30}$ Neighborhood deprivation scores were classified into tertiles reflecting low (0) to high (2) deprivation.

\section{Student characteristics}

At both baseline and follow-up, trained nurses measured child height, weight and waist circumference according to a standardized protocol. ${ }^{32}$ Percentage body fat and central adiposity were measured using DEXA Prodigy Bone Densitometer System, DF+14664 (GE Lunar Corporation, Madison, WI, USA). No reagents or chemicals were used. Age- and sexspecific BMI Z-scores were computed based on child height and weight according to the United States Centers for Disease Control and Prevention growth charts. ${ }^{33}$ Body fat percentage was calculated as $100 \times$ (total fat mass in grams)/(total fat mass in grams+total lean body mass in grams +total bone mass in grams). Percent central body was calculated as (truncal fat mass in grams/total body fat mass in grams) $\times 100$.

Child's daily physical activity was objectively measured using an actigraph activity monitor (accelerometer; Actigraph LS 7164 activity monitor, Actigraph LLC, Pensacola, FL, USA) over the course of 1 week. Participants wore an accelerometer during the whole day, except while bathing or during aquatic activities. ${ }^{34,35}$ Parents completed questionnaires at the baseline assessment to gather demographic information including child age, sex, highest educational level of the parents, (high school, pre-university level, technical or trade school, or university) and total annual family income in Canadian dollars. ${ }^{26}$ Parent height and weight were measured at baseline, and BMI was calculated according to standard formula. 
Data analysis strategy

We used k-cluster analysis with the 246 schools on the basis of the: (i) density of convenience stores around the school; (ii) density of fast-food outlets around the school; (iii) availability of healthful foods in the school; and (iv) the approval of the school menu by a nutritionist. We used analysis of variance to examine whether school types differed significantly in terms of the level of surrounding neighborhood material deprivation and social deprivation.

Once the clusters were defined, data were remerged to include all students $(N=431)$. We ran three separate linear models with BMI $Z$-scores, $\%$ body fatness and \% central body fat as outcomes. Generalized estimation equations were utilized to account for nesting of children within schools and to calculate appropriate confidence intervals. As all three outcomes were normally distributed, we estimated generalized linear models with an identity link function for each outcome variable.

The response rate for principals was 67 and $76 \%$ for items assessing the sale of heathy foods and the quality of the school menu, respectively. At follow-up, complete anthropometric data were available for $90 \%$ of our sample. Following recommendations on the treatment of missing data in longitudinal research, we performed multiple imputations with NORM software. ${ }^{28}$ Analyses were initially conducted using both imputed and nonimputed data. Both methods provided similar results; consequently, we report results that draw upon the imputed data for a more conservative estimate of regression associations. ${ }^{26}$

\section{RESULTS}

Descriptive statistics

In our sample, boys were slightly more represented than girls (54 vs $46 \%$ ). At the follow-up assessment, children had mean \% of central body fat of 42.5 (s.d.=4.90), compared to 40.6 at baseline assessment. The mean BMI Z-score at baseline was 0.63 (s.d.=1.14). The mean BMI Z-score at follow-up was 0.68 (s.d.=1.09). Finally, in terms of family demographics, the mean household income was 42344 CAD per year and 8\% of the children had at least one parent without a high school diploma. At the baseline assessment, $76 \%$ of children were in grades 2, 3 or 4, whereas $24 \%$ were in grades 5 or 6 .

\section{Cluster analyses}

We did not have a priori hypotheses about the number of school types we expected to emerge; therefore, our intention was to

Table 1. Sample characteristics according to cluster membership

\begin{tabular}{|c|c|c|c|c|c|c|c|}
\hline \multirow[t]{2}{*}{ School characteristics } & \multicolumn{2}{|c|}{$\begin{array}{l}\text { Type 1: Overall healthful school } \\
\qquad F E(\mathrm{~N}=110)\end{array}$} & \multicolumn{2}{|c|}{$\begin{array}{l}\text { Type 2: Unhealthful FE inside the } \\
\text { school }(\mathrm{N}=55)\end{array}$} & \multicolumn{2}{|c|}{$\begin{array}{l}\text { Type 3: Overall unhealthful } \\
\qquad F E(\mathrm{~N}=81)\end{array}$} & \multirow[t]{2}{*}{ P-value } \\
\hline & Mean (\%) & s.d. & Mean (\%) & s.d. & Mean (\%) & s.d. & \\
\hline Convenience store & 0.75 & 0.96 & 1.15 & 1.57 & 5.91 & 5.20 & $<0.001$ \\
\hline Fast food & 0.52 & 1.05 & 0.79 & 1.09 & 1.80 & 1.97 & $<0.001$ \\
\hline \multicolumn{8}{|l|}{ Cafeteria menu } \\
\hline \multicolumn{8}{|l|}{ Healthy food for sale } \\
\hline Always agree (\%) & 70 & - & 17 & - & 30 & - & $<0.001$ \\
\hline \multicolumn{8}{|l|}{ Child characteristics } \\
\hline BMI (Z-scores) & 0.62 & 1.06 & 0.75 & 1.07 & 0.64 & 1.06 & 0.557 \\
\hline Central adiposity (\%) & 41.80 & 4.81 & 43.53 & 4.91 & 42.97 & 4.44 & $<0.001$ \\
\hline Body fat $(\%)$ & 28.87 & 11.66 & 29.66 & 10.66 & 28.03 & 11.85 & 0.737 \\
\hline \multicolumn{8}{|l|}{ Family characteristics } \\
\hline Income (CAD) & 42870 & 18000 & 41426 & 19153 & 44065 & 19556 & 0.587 \\
\hline Parent education & & & & & & & $<0.001$ \\
\hline Two parents no high school & 1.2 & & 1.8 & & 1.2 & & \\
\hline One parent no high school & 9.7 & & 16.4 & & 3.7 & & \\
\hline One or two parents vocational/trade & 47.3 & & 36.4 & & 35.8 & & \\
\hline One or two parents university & 41.8 & & 45.5 & & 59.3 & & \\
\hline \multicolumn{8}{|l|}{ School characteristics } \\
\hline Material deprivation & & & & & & & 0.025 \\
\hline Lowest tertile & 37.6 & - & 38.3 & - & 7.4 & - & \\
\hline Middle tertile & 36.7 & - & 23.6 & - & 23.5 & - & \\
\hline Highest tertile & 25.7 & - & 38.2 & - & 69.1 & - & \\
\hline Social deprivation & & & & & & & $<0.001$ \\
\hline
\end{tabular}

Abbreviations: FE, food environment; PA, physical activity. Convenience stores and fast-food outlets reflect the mean number per $750 \mathrm{~m}$ radius of the school. Cafeteria menu and food for sale variables each reflects the principal's agreement with the statements: the cafeteria menu must be reviewed by a nutritionist; and the school sells food and drinks that conform to the principles of healthful nutrition. Each variable was dichotomized and scored as 0 (strongly agree) or 1 (agree, agree more or less, and strongly disagree). Parental education was scored as $1=$ high school, $2=$ pre-university level, $3=$ technical or trade school, or $4=$ university. PA measured using an accelerometer in counts per wear time. Material deprivation reflects the proportion of individuals without a high school diploma, who are unemployed and average income. Social deprivation reflects the proportion of people living alone, separated, divorced or widowed, or living in single-parent families. Neighborhood deprivation scores were classified into tertiles reflecting low to high deprivation. 
Table 2. Associations between school food environment types and child adiposity outcomes

\begin{tabular}{|c|c|c|c|}
\hline & BMI (Z-score), $\beta$ (Cl) & Body fat (\%), $\beta(C l)$ & Central adiposity (\%), $\beta(C l)$ \\
\hline \multicolumn{4}{|l|}{ Model 1 (unadjusted) } \\
\hline Type 2: Unhealthy FE inside & $0.14(-0.13$ to 0.40$)$ & $1.47(-1.32$ to 4.27$)$ & $2.01(0.83 \text { to } 3.20)^{* *}$ \\
\hline Type 3: Unhealthful overall FE & $-0.01(-0.24$ to 0.23$)$ & $0.43(-2.07$ to 2.92$)$ & $1.26(0.27 \text { to } 2.26)^{*}$ \\
\hline \multicolumn{4}{|l|}{ Model 2 (adjusted) } \\
\hline Type 2: Unhealthful FE inside & $0.11(-0.14$ to 0.36$)$ & $0.84(-1.64$ to 3.32$)$ & $1.48(0.33 \text { to } 2.63)^{*}$ \\
\hline Type 3: Unhealthful overall FE & $0.06(-0.16$ to 0.28$)$ & $1.24(-1.0$ to 3.48$)$ & $1.41(0.49 \text { to } 2.33)^{* *}$ \\
\hline PA (counts per $100 \mathrm{~min}$ ) & $-0.06(-0.11 \text { to }-0.001)^{*}$ & $-0.95(-1.48 \text { to }-0.42)^{* *}$ & $-0.09(-0.33$ to 0.16$)$ \\
\hline Sex $($ male $=1$, female $=2)$ & - & $4.06(2.06-6.05)^{* *}$ & $2.01(1.14 \text { to } 2.87)^{* *}$ \\
\hline Child age (months) & - & $-0.03(-0.12$ to 0.06$)$ & $0.07(0.04 \text { to } 0.11)^{* *}$ \\
\hline Parental education & $-0.18(-0.35 \text { to }-0.02)^{*}$ & $-1.62(-3.25$ to -0.01$)$ & $-0.71(-1.39 \text { to }-0.21)^{*}$ \\
\hline Family income (in $1000 \$$ ) & $0.00(-0.00$ to 0.01$)$ & $-0.01(-0.07$ to 0.05$)$ & $-0.01(-0.04$ to 0.02$)$ \\
\hline Mother's BMI & $0.05(0.04 \text { to } 0.06)^{* * *}$ & $0.47(0.31 \text { to } 0.62)^{* *}$ & $0.12(0.06 \text { to } 0.19)^{* * *}$ \\
\hline Father's BMI & $0.03(0.02 \text { to } 0.05)^{* *}$ & $0.38(0.20 \text { to } 0.57)^{* *}$ & $0.06(-0.02$ to 0.14$)$ \\
\hline
\end{tabular}

examine and compare solutions with up to 10 clusters using $\mathrm{K}$-means clustering technique. In the 3-cluster solution, wherein each child was represented only once in each cluster, all of the selected variables contributed significantly to differentiating the school type. Fit statistics and cluster size considerations supported the 3-cluster solution. ${ }^{29}$ As the 4-cluster solution did not provide a better fit, we retained the 3 -cluster solution.

To facilitate discussion, we provide labels and descriptive names for each of the school groupings defined by our cluster analysis. Type 1 schools ( $N=110$ schools) are referred to as 'Overall healthful food environment'. Principals in these schools 'strongly agreed' that the school menu had been reviewed by a nutritionist and that food sold inside the school was healthful. Furthermore, these schools were surrounded by a low density of fast food and convenience stores. Type 2 schools ( $N=55$ schools) are referred to as 'Unhealthful food environment inside the school'. At these schools, principals were less likely to strongly agree that menus were reviewed by a nutritionist and healthful food was available for sale. In contrast, these schools were surrounded by a low density of fast-food outlets and convenience stores. Finally, type 3 schools ( $N=81$ schools) are referred to as 'Overall unhealthful food environment'. This group of schools was characterized by a moderately unhealthful food environment inside the school and the highest density of fast-food outlets and convenience stores surrounding the school. Table 1 shows descriptive statistics for school food environment characteristics, neighborhood deprivation and sociodemographic characteristics by school type.

To address the hypothesis that schools in more unhealthful food environments are located in neighborhoods with higher levels of social and material deprivation, we conducted an analysis of variance with school type as the between-subject factor, and neighborhood social and material deprivation as dependent variables. Significant group differences between school types on material and social deprivation emerged, $(F(2,243)=3.75$, $P<0.025$ and $F(2,243)=36.42, P<0.0001$, respectively). Using Tukey corrections, post hoc analyses revealed that overall healthful schools were significantly lower in material deprivation than the overall unhealthful schools (mean $=0.88$ vs 1.21 ; Table 1 ). Overall unhealthful schools were situated in areas with significantly greater social deprivation than both overall healthful and unhealthful inside school types (1.62 vs 0.77 and 0.82 ).

Table 2 shows unadjusted associations (model 1) as well as associations adjusted for child physical activity, age in months, sex, family income, mother's and father's BMI, and parental education (model 2 ) between school type and child adiposity outcomes. In all models, school type 1, reflecting an overall healthful food environment inside and surrounding the school, is used as the reference group. In model 1, schools characterized by having the most unhealthful food environment inside the school and schools with overall unhealthful food environments were associated with greater $\%$ central adiposity 2 years later $(\beta=2.01$ (95\% Cl, 0.83 to 3.20$), P<0.01$ and, $\beta=1.26,(95 \% \mathrm{Cl}, 0.27$ to 2.26$)$ $P<0.05$, respectively). School types were not significantly associated with child BMI Z-scores or \% body fat, although associations were in the expected direction, with children attending schools with an overall unhealthful food environment showing higher BMI Z-scores and overall \% body fat.

In model 2, both unhealthful school types remained significant predictors of child central adiposity $(\beta=1.48,(95 \% \mathrm{Cl}, 0.33$ to 2.63$)$ $P<0.05$, and $\beta=1.41,(95 \% \mathrm{Cl}, 0.49$ to 2.33$) P<0.01)$. School types remained nonsignificant predictors of BMI Z-scores and overall \% body fat. Higher levels of physical activity were associated with lower BMI Z-score and overall body fat $(\beta=-0.06,(95 \% \mathrm{Cl},-0.11$ to -0.001$) P<0.05$, and $\beta=-0.95,(95 \% \mathrm{Cl},-1.48$ to -0.42$)$ $P<0.01$, respectively). Higher parental education was associated lower BMI Z-score, $(\beta=-0.18,(95 \% \mathrm{Cl},-0.35$ to -0.02$) P<0.01)$, and central adiposity $(\beta=-0.71,(95 \% \mathrm{Cl},-1.39$ to -0.21$)$ $P<0.05)$. Finally, being a female predicted greater body fatness $(\beta=4.06,(95 \% \mathrm{Cl}, 2.06$ to 6.05$) P<0.001)$ and central adiposity $(\beta=2.01$, (95\% Cl, 1.14 to 2.87$) P<0.01)$.

\section{DISCUSSION}

The Going the Healthy Route at School Policy, implemented in the province of Quebec, aims to ensure that all children in both public and private schools have equal access to food environments that promote health. ${ }^{16}$ Our results suggest that variations exist in the types of food environments to which students are exposed. Less than half of the children in our sample (45\%) attended schools characterized by a healthful food environment inside and surrounding the school. In contrast, a majority of children in the current study (55\%) were exposed to an unhealthful school food environment.

As is recommended in the measurement literature, we attempted to validate our cluster solution by examining associations with school neighborhood characteristics and child adiposity outcomes. ${ }^{36}$ Schools with overall less healthful food environments were located in neighborhoods with higher levels of material and social deprivation. This finding is consistent with previous research 
showing that more disadvantaged neighborhoods tend to have more obesogenic features. ${ }^{23,37}$

Schools located in more disadvantaged areas might face specific barriers that interfere with the implementation of healthful food policies. For example, it may be too costly to provide healthy foods for students or to hire a nutritionist to assess the quality of food offered. Alternately, competing priorities may prevail. Previous work suggests that concerns over the loss of revenue from food sales (for example, bake sales, pizza day and so on) may impede the successful implementation of healthy school food policies. ${ }^{14}$ Similarly, inadequate training provided to staff may also compromise their ability to promote healthful eating habits in the school.

The majority of school-based interventions have targeted the indoor food environment. Our results suggest offering healthful food options within the school remains a promising strategy for the prevention of child adiposity in at-risk populations. Attending schools surrounded by more fast-food outlets and convenience stores also placed students at risk of greater central adiposity 2 years later. This is likely to be the case because the proximity of these establishments can increase access to unhealthy foods and snacking opportunities. The proximity of fast-food outlets may also influence eating habits beyond school hours by repeatedly exposing youth to advertisements for unhealthy 'brands', which may then shape longer-term eating habits and preferences.

We observed no associations between school food environment and child overall BMI Z-score or overall \% body fat. Although very small effects may have been missed, it is possible that dietary behaviors are more strongly associated with central body fat than with overall BMI, whereas overall body fat and BMI are more related to physical activity. In our analyses, we found that physical activity was predictive of lower BMI Z-score and total body fatness but not of lower central adiposity. This suggests that diet and physical activity may influence child weight gain through different pathways. Nevertheless, we believe that the present findings remain of practical importance. In particular, unlike BMI, a higher central adiposity among both obese and non-obese children represents a stronger predictor of later cardiovascular disease, hypertension and insulin resistance. ${ }^{7,38-41}$

Previous studies have failed to find significant associations between the school food environment and child health outcomes. ${ }^{42}$ It is possible that the use of cluster analyses rather than variable-based approaches in the present study allowed us to better capture how different naturally occurring groupings of inter-related factors influence adiposity outcomes. This differs from variable-based approaches, which consider the unique contribution of distinct school food environments features on health outcomes. The present study was also enriched by the use of a prospective longitudinal design, which allowed us to examine the influence of exposure over a 2-year time span. Finally, in our investigation, it was possible to remove variance associated with certain baseline individual characteristics to better isolate associations between exposure to an obesogenic environment and child health.

The effect sizes for associations between school type and adiposity associated with school type were small. Nonetheless, our results suggest that food environments contribute to the web of environmental risks factors associated with unhealthful childhood weight gain. Furthermore, the school food environment represents a modifiable factor, which can be strategically targeted to reduce socioeconomically-based disparities in childhood health.

Our study presented certain limitations. First, our measurement of the food environment inside the schools was based on interviews with principals. Consequently, it is possible that these reports were biased by social desirability or recall issues. Additional interviews when food services are outsourced may be warranted but those responsible may have little knowledge of other key information related to the school environment. Despite this limitation, errors due to possible misclassification of schools are unlikely to give rise to spurious correlations, although they may have led us to underestimate the true magnitude of the associations. Second, our results examining the existence of school types were exploratory in nature and other research should be conducted to examine whether our findings are replicable and generalizable to other samples. Given the observational design of our research, it is not possible to rule out the possibility that school preferences of children and their families might explain the observed associations. Nevertheless, to limit this possibility, we included parent education and income, two strong indicators of socioeconomic status, as well as child baseline physical activity as control variables in our analyses. Finally, our sample was constrained to Caucasian youth at risk of developing cardiometabolic disease. To better assess the generalizability of our findings, we invite replications with lower-risk and ethnically diverse populations.

\section{CONCLUSION}

Childhood obesity presents important challenges for public health. The most successful strategies for countering child obesity are those that are preventive in nature and help create the types of environments that allow children to engage in plenty of physical activity while also favoring healthful eating habits. ${ }^{43,44}$ Indeed, carefully implemented interventions that target food environments inside schools have been shown to improve the quality of children's diets. ${ }^{15,45}$ The present results suggest that more efforts be aimed at improving school food environments both inside and surrounding school neighborhoods, particularly in schools facing higher levels of neighborhood deprivation. Research aimed at identifying strategies for overcoming barriers, either social or economic, that impede the successful implementation of healthful food policies in economically disadvantaged schools is also likely to be beneficial in reducing disparities in child health. We recommend that increased efforts be devoted to creating healthier food environments in elementary schools, where children spend a large proportion of their time, consume a large portion of their daily caloric intake and form potentially lifelong dietary preferences and habits.

\section{CONFLICT OF INTEREST}

The authors declare no conflict of interest.

\section{ACKNOWLEDGEMENTS}

QUALITY study was conducted by members of TEAM PRODIGY, an inter-university research team including Université de Montréal, Concordia University, Université Laval and McGill University. The QUALITY cohort was funded by the Canadian Institutes of Health Research (\#OHF-69442, \#NMD-94067, \#MOP-97853 and \#MOP-119512), the Heart and Stroke Foundation of Canada (\#PG-040291), and Fonds de recherche du Québec-Santé (FRQS). Dr Marie Lambert (July 1952-February 2012), pediatric geneticist and researcher, initiated the QUALITY cohort. Her leadership and devotion to QUALITY will always be remembered and appreciated. Finally, we are grateful to all the families that participate in the QUALITY cohort. YK holds a CIHR Applied Public Health Chair in Urban Interventions and Population Health. TB holds a FRQS Senior Research Scholar Award. MH holds a FRQS Junior 1 salary award.

\section{AUTHOR CONTRIBUTIONS}

Caroline Fitzpatrick wrote the first draft of this paper and has received no honorarium, grant or form of payment to produce the manuscript. Tracie A Barnett, Geetanjali Datta, Yan Kestens, Melanie Henderson, Katherine GrayDonald and Caroline Fitzpatrick all take entire responsibility for this manuscript. 


\section{REFERENCES}

1 Gortmaker SL, Taveras EM. Who becomes obese during childhood--clues to prevention. New Eng J Med 2014; 370: 475-476.

2 Dietz WH, Gortmaker SL. Preventing obesity in children and adolescents. Annu Rev Public Health 2001; 22: 337-353.

3 Active Healthy Kids Canada 2014. Is Canada in the Running? The 2014 Active Healthy Kids Canada Report Card on Physical Activity for Children and Youth. Toronto: Active Healthy Kids Canada, 2014. Available at https://www.participac tion.com/sites/default/files/downloads/Participaction-2014FullReportCard-Cana dalnTheRunning_0.pdf (accessed 12 September 2016).

4 Pate R, Davis M, Robinson T, Stone E, McKenzie T, Young J. Promoting physical activity in children and youth a leadership role for schools: a scientific statement from the American Heart Association Council on Nutrition, Physical Activity, and Metabolism (Physical Activity Committee) in collaboration with the councils on Cardiovascular Disease in the Young and Cardiovascular Nursing. Circulation 2006; 114: 1214-1224.

5 Veugelers P, Schwartz M. Comprehensive school health in Canada. Can J Public Health 2010; 101(Suppl 2): S5-S8.

6 Gleason P, Suitor C. Food for Thought: Children's Diets in the1990s. Mathematica Policy Research Inc: Princeton, NJ, USA, 2001.

7 Poti J, Slining M, Popkin B. Where are kids getting their empty calories? Stores, schools, and fast-food restaurants each played an important role in empty calorie intake among US children during 2009-2010. J Acad Nutr Diet 2013; 114: 908-917.

8 Briefel R, Crepinsek M, Cabili C, Wilson A, Gleason P. School food environments and practices affect dietary behaviors of US public school children. J Am Diet Assoc 2009; 109: S91-S107.

9 McKenna M. Issues in implementing school nutrition policies. Can J Diet Pract Res 2003; 64: 208-213.

10 Mâsse L, Naiman D, Naylor P-J. From policy to practice: implementation of physical activity and food policies in schools. Int J Behav Nutr Phys Act 2013; 10: 71

11 Taylor J, Maclellan D, Caiger J, Hernandez K, McKenna M, Gray B et al. Implementing elementary school nutrition policy: principals' perspectives. Can J Diet Pract Res 2011; 72: 176.

12 Downs S, Farmer A, Quintanilha M, Berry T, Mager D, Willows $\mathrm{N}$ et al. From paper to practice: barriers to adopting nutrition guidelines in schools. J Nutr Educ Behav 2012; 44: 114-122.

13 Mullally M, Taylor J, Kuhle S, Bryanton J, Hernandez K, MacLellan D et al. A province-wide school nutrition policy and food consumption in elementary school children in Prince Edward Island. Can J Public Health 2010; 101: 40-43.

14 Baril G School Food Policies: a Knowledge Synthesis on the Implementation Process. 2008. Available at https://http://www.inspq.qc.ca/pdf/publications/858_ SchoolfoodPol_final.pdf.

15 Siega-Riz A, El Ghormli L, Mobley C, Gillis B, Stadler D, Hartstein J et al. The effects of the HEALTHY study intervention on middle school student dietary intakes. The Int J Behav Nutri Phys Act 2011; 8: 7.

16 Ministry of Education S, and Leisure. Going the Healthy Route at School. Available at http://www.education.gouv.qc.ca/fileadmin/site_web/documents/dpse/adapta tion_serv_compl/Goingtothehealthyrouteatschool_policyframework_AN.pdf. 2007.

17 Watts A, Mâsse L, Naylor P-J. Changes to the school food and physical activity environment after guideline implementation in British Columbia, Canada. Int J Behav Nutr Phys Act 2014; 11: 50.

18 Fung C, Mclsaac J, Kuhle S, Kirk S, Veugelers P. The impact of a population-level school food and nutrition policy on diet intake and body weights of Canadian children. Prev Med 2013; 57: 934-940.

19 Vine M, Elliot S. Examining local-level factors shaping school nutrition policy implementation in Ontario, Canada. Public Health Nutr 2014; 17: 1290-1298.

20 Austin S, Melly S, Sanchez B, Patel A, Buka S, Gortmaker S. Clustering of fast-food restaurants around schools: a novel application of spatial statistics to the study of food environments. Am J Public Health 2005; 95: 1575-1581.

21 Day P, Pearce J. Obesity-promoting food environments and the spatial clustering of food outlets around schools. Am J Prev Med 2011; 40: 113-121.

22 Finkelstein D, Hill E, Whitaker R. School food environments and policies in US public schools. Pediatrics 2008; 122: e251-e259.
23 Kestens Y, Daniel M. Social inequalities in food exposure around schools in an urban area. Am J Prev Med 2010; 39: 33-40.

24 Wang Y, Beydoun M. The obesity epidemic in the United States-gender, age, socioeconomic, racial/ethnic, and geographic characteristics: a systematic review and meta-regression analysis. Epi Rev 2007; 29: 6-28.

25 Woolf S, Braveman P. Where health disparities begin: the role of social and economic determinants and why current policies may make matters worse. Health Affairs 2011; 30: 1852-1859.

26 Lambert M, Van Hulst A, O'Loughlin J, Tremblay A, Barnett TA, Charron $\mathrm{H}$ et al. Cohort profile: the Quebec adipose and lifestyle investigation in youth cohort. Int J Epidemiol 2012; 41: 1533-1544.

27 Grundy S, Cleeman J, Daniels S, Donato K, Eckel R, Franklin B et al. Diagnosis and management of the metabolic syndrome an American Heart Association/National Heart, Lung, and Blood Institute scientific statement. Circulation 2005; 112: 2735-2752.

28 Greves H, Rivara F. Report card on school snack food policies among the United States' largest school districts in 2004-2005: room for improvement. Int J Behav Nutr Phys Act 2006; 3: 1.

29 Pearlman D, Dowling E, Bayuk C, Cullinen K, Thacher A. From concept to practice: using the School Health Index to create healthy school environments in Rhode Island elementary schools. Prev Chronic Dis 2005; 2: 1-16.

30 Brener N, Kann L, Smith T. Reliability and validity of the School Health Policies and Programs Study 2000 questionnaires. J School Health 2003; 73: 29-37.

31 Clary MC, Kestens Y. Field validation of secondary data sources: a novel measure of representativity applied to a Canadian food outlet database. Int J Behav Nutr Phys Act 2013; 10: 77.

32 Buck C, Bornhorst C, Pohlabeln H, Huybrechts I, Pala V, Reisch L, Pigeot I. Clustering of unhealthy food around German schools and its influence on dietary behavior in school children: a pilot study. Int J Behav Nutr Phys Act 2013; 10: 65.

33 Paradis G, Lambert M, O'Loughlin J, Lavallée C, Aubin J, Berthiaume P et al. The Quebec Child and Adolescent Health and Social Survey: design and methods of a cardiovascular risk factor survey for youth. Can J Cardiol 2003; 19: 523-531.

34 Lau D, Douketis J, Morrison K, Hramiak I, Sharma A, Ur E. Canadian clinical practice guidelines on the management and prevention of obesity in adults and children. Can Med Assoc J 2007; 176: S1-S13.

35 Colley R, Gorber S, Tremblay M. Quality control and data reduction procedures for accelerometry-derived measures of physical activity. Health Rep 2010; 21: 63-69.

36 Hair J, Black W, Babin B, Anderson R. Multivariate Data Analysis, 7th edn. Pearson: Upper Sadle River, NJ, USA, 2010.

37 Van Hulst A, Barnett TA, Gauvin L, Daniel M, Kestens Y, Bird M et al. Associations between children's diets and features of their residential and school neighborhood food environments. Can J Public Health 2012; 103(Suppl 3): S48-S54.

38 Meininger J, Brosnan C, Eissa M, Nguyen T, Reyes L, Upchurch S et al. Overweight and central adiposity in school-age children and links with hypertension. $J$ Pediatr Nursing 2010; 25: 119-125.

39 Arnberg K, Larnkjær A, Michaelsen K, Mølgaard C. Central adiposity and protein intake are associated with arterial stiffness in overweight children. J Nutr Educ Behav 2010; 142: 878-885.

40 Després J-P, Lemieux I, Bergeron J, Pibarot P, Mathieu P, Larose E et al. Abdominal obesity and the metabolic syndrome: contribution to global cardiometabolic risk. Arterioscler Thromb Vasc Biol 2008; 28: 1039-1049.

41 Gower B, Nagy T, Goran M. Visceral fat, insulin sensitivity, and lipids in prepubertal children. Diabetes 1999; 48: 1515-1521.

42 An R, Sturm R. School and residential neighborhood food environment and diet among California youth. Am J Prev Med 2012; 42: 129-135.

43 Ashe M, Graff S, Spector C. Changing places: policies to make a healthy choice the easy choice. Public Health 2011; 125: 889-895.

44 Ebbeling C, Pawlak D, Ludwig D. Childhood obesity: public-health crisis, common sense cure. Lancet 2002; 360: 473-482.

45 Fung C, Kuhle S, Lu C, Purcell M, Schwartz M, Storey K et al. From 'best practice' to 'next practice': the effectiveness of school-based health promotion in improving healthy eating and physical activity and preventing childhood obesity. Int J Behav Nutri Phys Act 2012; 9: 27. 